www.nature.com/ejhg

\title{
PTPN11 mutation in a large family with Noonan syndrome and dizygous twinning
}

\author{
Els Schollen ${ }^{1}$, Gert Matthijs ${ }^{1}$, Marc Gewillig ${ }^{2}$, Jean-Pierre Fryns ${ }^{1}$ and Eric Legius*,1 \\ ${ }^{1}$ Department of Human Genetics, University Hospitals Leuven, Belgium; ${ }^{2}$ Department of Pediatric Cardiology, \\ University Hospitals Leuven, Belgium
}

\begin{abstract}
Noonan syndrome (NS, MIM 163950) is an autosomal dominant condition characterised by facial dysmorphy, congenital cardiac defects and short stature. Recently missense mutations in PTPN11, the gene encoding the nonreceptor protein tyrosine phosphatase SHP-2 on 12q24, were identified in $50 \%$ of analysed Noonan cases. A large four-generation Belgian family with NS and some features suggestive of cardio-facio-cutaneous syndrome (CFC) was previously used to fine map the Noonan syndrome candidate region to a $5 \mathrm{CM}$ region in 12q24. We now report the identification of a mutation (Gln79Arg) in the PTPN11 gene in this large family. In D. melanogaster and C. elegans the PTPN11 gene has been implicated in oogenesis. In this family two affected females had dizygous twins. This suggests that PTPN11 might also be involved in oogenesis and twinning in humans.
\end{abstract}

European Journal of Human Genetics (2003) 11, 85 -88. doi:10.1038/sj.ejhg.5200915

Keywords: Noonan syndrome; cardio-facio-cutaneous syndrome; PTPN1 1; DHPLC

\section{Introduction}

Noonan syndrome (MIM 163950) is an autosomal dominant syndrome characterised by several features such as a typical facial dysmorphy (hypertelorism, downward eyeslant, broad nasal tip, low-set posteriorly rotated ears), short stature, short webbed neck, typical chest deformity and cardiac anomalies. ${ }^{1}$ The syndrome is relatively common with an incidence of 1 in 1000 to 2500 live births. Two large families were used to map the syndrome to a $5 \mathrm{~cm}$ interval between markers D12S84 and D12S1341 on chromosome 12q24.,3 Recently missense mutations in PTPN11 (MIM 176876) have been found in 9 NS families and four individual cases, corresponding to $50 \%$ of the cases analysed. Genetic heterogeneity has also been shown by lack of linkage to $12 \mathrm{q} 24$ of several smaller nuclear families. ${ }^{4}$

PTPN11 encodes the nonreceptor protein tyrosine phosphatase SHP-2, an enzyme participating in several signal transduction cascades downstream of receptors for growth

\footnotetext{
*Correspondence: Eric Legius, Centre for Human Genetics, University Hospitals Leuven, Herestraat 49, 3000 Leuven, Belgium.

Tel: (32) 16345903; Fax: (32) 16346051;

E-mail: Eric.Legius@med.kuleuven.ac.be

Received 20 March 2002; revised 2 October 2002; accepted 7 October 2002
}

factors, cytokines and hormones. ${ }^{5}$ The crystal structure of SHP-2 revealed an auto-inhibitory mechanism of the catalytic activity by the N-terminal SH-2 domain. ${ }^{6}$ All reported Noonan syndrome mutations are clustered in this $\mathrm{SH}-2$ domain or the phosphotyrosine phosphatase domain (PTP) and switch the enzyme to its active conformation. ${ }^{7}$ The pathogenesis of Noonan syndrome is therefore due to excessive SHP-2 activity.

We screened the PTPN11 gene by DHPLC in a large, fourgeneration Belgian family previously used to fine map the NS region. In this family some individuals present with NS and features suggestive of $\mathrm{CFC}^{8}$ and others with NS features only. 3,9

\section{Subjects, material and methods}

Subjects

The family has previously been extensively described. ${ }^{3,9}$ Essentially we sampled 10 affected individuals, seven unaffected relatives and three spouses (Figure 1). Most affected individuals have a typical Noonan syndrome phenotype with the typical facial dysmorphy and pale grey-blue eyes. Individual III2 was treated for a ventricular septal defect and pulmonic valve stenosis. Individual III12 is severely mentally retarded and lives in an institution for mentally handicapped adults. In addition he has a pulmonic valve 


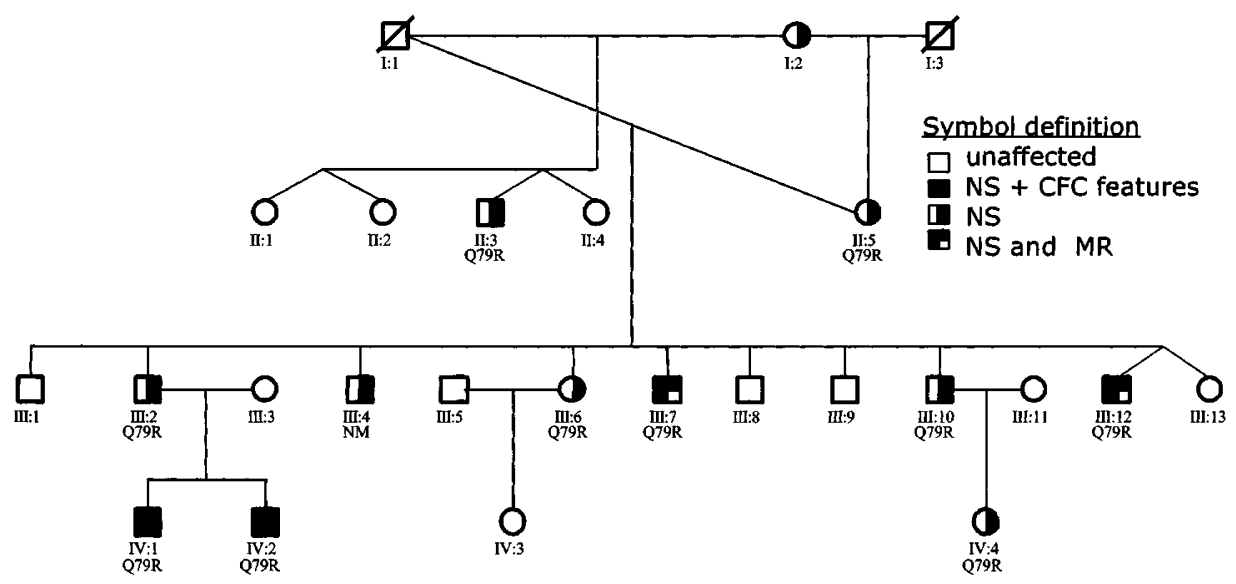

Figure 1 Pedigree of the NS family. Only the available family members of the first two generations are shown. No material was available from individual III4 (NM). All affected individuals are heterozygous for the mutation Q79R. The mutation was not found in the analysed normal family members.

stenosis. The two brothers IV1 and IV2 presented with a phenotype suggestive of CFC: besides the facial dysmorphy and growth retardation, they also have a dry scaly skin and sparse scalp hair. They are also mildly mentally retarded. Individual IV4 has a pulmonic valve stenosis treated by balloon dilatation. She was investigated for a bleeding tendency. A reduced level of clotting factor XI was found in addition to a platelet aggregation abnormality. She has one café-au-lait spot and is currently treated with human growth hormone because of short stature. In this family all individuals with NS syndrome and normal intelligence experienced learning difficulties at school.

\section{DHPLC screening of PTPN11}

The genomic structure and intron boundary sequences were deduced from the genomic contig NT030120 and mRNA sequence NM002834 in combination with the mRNA-genomic alignments at NCBI (Locus ID 5781). PCR primers (typically $20 \mathrm{bp}$ long) were designed for each exon individually with primer-3 software (http://www-genome. wi.mit.edu/cgi-bin/primer/primer3_www.cgi/). Amplicons typically include a $50 \mathrm{bp}$ intronic sequence on either site of the exon. Primer sequences are available on request.

PCR amplifications were done in $50 \mu \mathrm{l}$ with $1 \times$ PCR buffer (Roche, Mijdrecht, the Netherlands); 25 pmol of each primer, $0.2 \mathrm{~mm}$ dNTPs, $2 \mathrm{U}$ Taq polymerase (Roche) and 200 ng genomic DNA. All PCR mixes were amplified with the same touch down program: $95^{\circ}, 5 \mathrm{~min}, 10$ cycles of $\left(95^{\circ} \mathrm{C}\right.$ for $30 \mathrm{~s}, 65^{\circ} \mathrm{C}\left(-1^{\circ} \mathrm{C} /\right.$ cycle $)$ for $30 \mathrm{~s}, 72^{\circ} \mathrm{C}$ for $\left.30 \mathrm{~s}\right)$, 25 cycles of $\left(95^{\circ} \mathrm{C}\right.$ for $30 \mathrm{~s}, 55^{\circ} \mathrm{C}$ for $30 \mathrm{~s}, 72^{\circ} \mathrm{C}$ for $\left.30 \mathrm{~s}\right)$ and a final extension at $72^{\circ} \mathrm{C}$ for $5 \mathrm{~min}$.

PCR amplification is followed by a denaturation at $95^{\circ} \mathrm{C}$ for $2 \mathrm{~min}$, slow cooling to $45^{\circ} \mathrm{C}$ (in $30 \mathrm{~min}$ ) and a final incubation at $45^{\circ}$ for $30 \mathrm{~min}$ to allow heteroduplexes to form.
DHPLC screening was done using a WAVE 3500HT system (Transgenomic, Cheshire, UK). Typically $7 \mu \mathrm{l}$ of PCR product was injected on the DNA-sep column (Transgenomic). Gradients and column temperatures were used as predicted by the Wavemaker 4.1 software and are available on request.

Amplicons with an aberrant elution profile were subsequently sequenced with Big-dye terminator cycle sequencing (Applied Biosystems, Foster City, CA, USA) as recommended by the manufacturer and analysed on an ABI-3100 (Applied Biosystems).

\section{Results}

Amplicons of exon 3 resulted in an aberrant elution pattern on DHPLC for all affected individuals compared to the control samples. Sequencing identified an $A>G$ transition in exon 3 at nucleotide position 236, resulting in Gln79Arg or Q79R (Figure 2). Samples of non-affected relatives revealed no heteroduplexes and normal sequence for exon 3.

The remaining 13 exons were screened for mutations by DHPLC in three affected individuals (III2, III10, II5) and one normal control (III11). No other abnormalities were detected.

\section{Discussion}

We describe here a PTPN11 mutation in a large family with NS. The same Q79R mutation was also reported in one NS family and one NS individual by Tartaglia et $a l^{7}$ and five more cases were described by Tartaglia et $a l^{10}$ in 2002. Gln79 is a residue of the $\alpha \mathrm{B}$ helix of the $\mathrm{N}-\mathrm{SH} 2$ domain, which is involved in the polar interaction of the PTP domain with the N-SH2 domain in the inhibitory state. ${ }^{6}$ Changing the very basic Gln79 to Arg might disturb this interaction and favour the active conformation of SHP-2. ${ }^{7}$ 


\section{a}

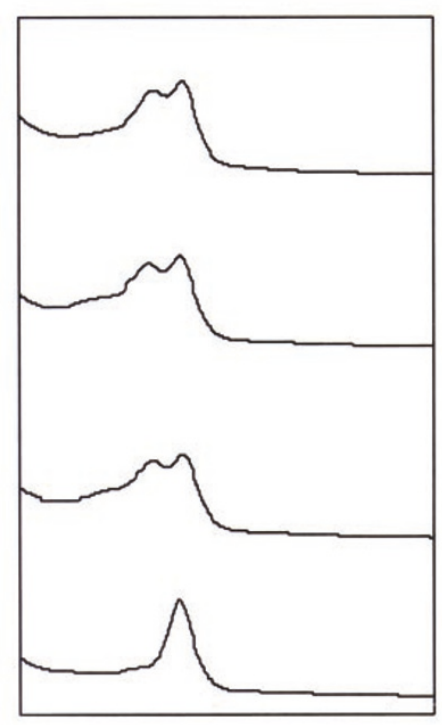

b

III:2

III: 10

II:5

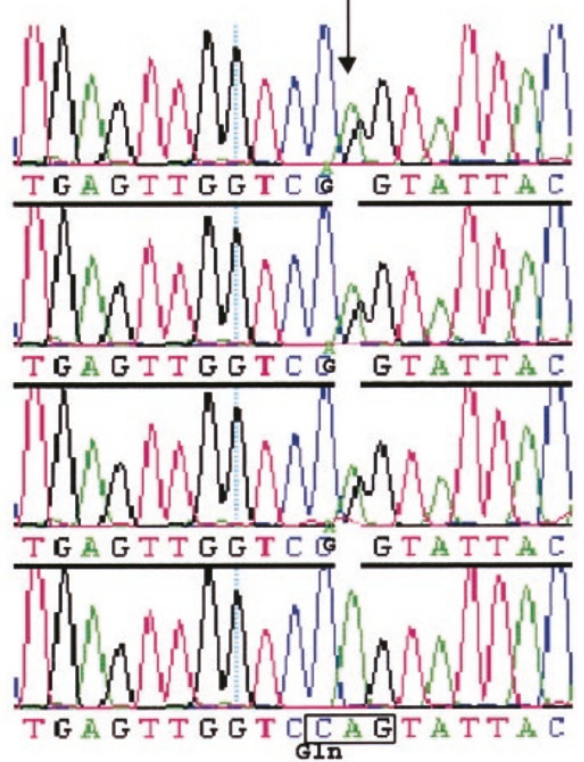

Figure 2 DHPLC (a) and sequencing results (b) of exon3 for individuals III2, III10, II5, III11. The mutation is present in the affected individuals III2, III10 and II5 and not in the unaffected relative III11.

In this family some relatives with the Q79R mutation have a Noonan syndrome phenotype and others were described with features suggestive of CFC. ${ }^{3,9}$ At this moment however one cannot conclude that these individuals had classical CFC syndrome. Further PTPN11 mutation analysis in a large group of patients with classical CFC syndrome will show if there is a relation between CFC and PTPN11. Preliminary data show no PTPN11 mutations in the first series of CFC patients. ${ }^{11,12}$

A remarkable finding in this large NS family is the presence of three dizygotic twins in the offspring of two affected females. A dizygotic twin in the offspring of an affected female is also observed in the other large NS family with linkage to $12 \mathrm{q} 24 .^{2}$ The C. elegans (PTP2) and D. melanogaster (Corkscrew) homologues of human SHP-2 are involved in oogenesis. ${ }^{13,14}$ C. elegans hermaphrodites homozygous for the ptp-2 (op194) loss of function mutation exhibit a semisterile phenotype with low numbers of abnormally large oocytes. PTP-2 has been described as an essential component of a signalling cascade that regulates normal oogenesis in C. elegans. ${ }^{13}$ Transcripts from corkscrew are detected in the germline during oogenesis in Drosophi$l a{ }^{14}$ and are important in the establishment of dorsal follicle cell fates. Therefore it seems possible that hyperfunction of PTPN11 in humans might result in multiple ovulation and an increased risk of dizygous twinning. Further mutation analysis in NS families will show if twinning is indeed more frequent in PTPN11 mutation positive females.

\section{Acknowledgements}

The authors want to acknowledge the expert assistance of Elly Pijkels in collecting clinical data and blood samples from this family. This research is sponsored in part by the Belgian Foundation for Research in Paediatric Cardiology. E Schollen is part-time clinical researcher of the Fonds voor Wetenschappelijk Onderzoek Vlaanderen (FWOVlaanderen).

\section{References}

1 Allanson JE: Noonan syndrome. J Med Genet 1987; 24: 9-13.

2 Jamieson CR, van der Burgt I, Brady AF et al: Mapping a gene for Noonan syndrome to the long arm of chromosome 12. Nature Genet 1994; 8: 357-360.

3 Legius E, Schollen E, Matthijs G, Fryns JP: Fine mapping of Noonan/cardio-facio cutaneous syndrome in a large family. Eur $J$ Hum Genet 1998; 6: $32-37$.

4 Van der Burgt I, Brunner H: Genetic heterogeneity in Noonan syndrome: evidence for an autosomal recessive form. Am J Med Genet 2000; 94: 46-51.

5 Feng GS: Shp-2 tyrosine phosphatase: signaling one cell or many. Exp Cell Res 1999; 253: 47-54.

6 Hof P, Pluskey S, Dhe-Paganon S, Eck MJ, Shoelson SE: Crystal structure of the tyrosine phosphatase SHP-2. Cell 1998; 92: 441 450.

7 Tartaglia M, Mehler EL, Goldberg R et al: Mutations in PTPN11, encoding the protein tyrosine phosphatase SHP-2, cause Noonan syndrome. Nat Genet 2001; 29: 465-468.

8 Reynolds JF, Neri G, Herrmann JP et al: New multiple congenital anomalies/mental retardation syndrome with cardio-facio-cutaneous involvement - the CFC syndrome. Am J Med Genet 1986; 25: $413-427$. 
9 Fryns JP, Volcke P, Van den Berghe H: The cardio-facio-cutaneous (CFC) syndrome: autosomal dominant inheritance in a large family. Genet Couns 1992; 3: 19-24.

10 Tartaglia M, Kalidas K, Shaw A et al: PTPN11 mutations in Noonan syndrome: molecular spectrum, genotype-phenotype correlation, and phenotypic heterogeneity. Am J Hum Genet 2002; 70: $1555-1563$.

11 Peiffer AP, Bamshad MB, Opitz JO, Viskochil DV, Leppert ML, Carey JC: Searching for PTPN11 mutations in CFC and Costello syndrome patients.. Am J Hum Genet 2002; 71: A525.

12 Kavamura I, Zollino M, Pomponi MG et al: Molecular and cytogenetic evidence that cardiofaciocutaneous (CFC) syndrome is distinct from Noonan syndrome (NS) and that it's locus is not in the chromosome region 12q21.2q22. Am J Hum Genet 2002; 71: A240.
13 Gutch MJ, Flint AJ, Keller J et al: The Caenorhabditis elegans SH2 domain-containing protein tyrosine phosphatase PTP-2 participates in signal transduction during oogenesis and vulval development. Genes Dev 1998; 12: 571-585.

14 Perkins LA, Johnson MR, Melnick MB et al: The nonreceptor protein tyrosine phosphatase corkscrew functions in multiple receptor tyrosine kinase pathways in Drosophila. Dev Biol 1996; 180: $63-81$. 